\title{
In Vitro and In Vivo Toxicity Evaluation of Colloidal Silver Nanoparticles Used in Endodontic Treatments
}

\author{
Aline Satie Takamiya, DDS, PbD, * Douglas Roberto Monteiro, DDS, PhD, * \\ Daniel Galera Bernabé, DDS, PhD, ${ }^{+}$Luiz Fernando Gorup, PhD, ${ }^{\neq}$ \\ Emerson Rodrigues Camargo, PbD, ${ }^{\neq}$João Eduardo Gomes-Filbo, DDS, PhD, \\ Sandra Helena Penba Oliveira, PhD, and Debora Barros Barbosa, DDS, PhD"
}

\section{Ahstract}

Introduction: Silver nanoparticles have been used for different purposes in dentistry, including endodontic treatments. The aim of this study was to determine the cytotoxicity of different types of silver nanoparticles on mouse fibroblast cell line L929 and the reaction of subcutaneous connective tissue of Wistar rats to these nanoparticles. Methods: Silver nanoparticles of an average size of $5 \mathrm{~nm}$ were synthesized with ammonia (SNA) or polyvinylpyrrolidone (SNP). 1929 was exposed to SNA and SNP $(0.1-100 \mu \mathrm{g} / \mathrm{mL})$, and 3-(4,5-dimethylthiazol-2-yl)-2,5-diphenyltetrazolium bromide and enzyme-linked immunosorbent assays were performed after 6,24 , and 48 hours. Culture medium was used as the control. Sixteen rats received, individually, 3 polyethylene tubes filled with a fibrin sponge embedded in $100 \mu \mathrm{L}$ SNA or SNP $(1 \mu \mathrm{g} / \mathrm{mL})$. A fibrin sponge with no embedding was the control. Tissue reaction was performed qualitatively and quantitatively after 7, 15, 30, and 90 days of implantation in the dorsal connective tissue of Wistar rats. Results: SNA and SNP were cytotoxic to L929 in higher concentrations, with SNA significantly more toxic than SNP. SNA and SNP did not induce significant interleukin$1 \beta$ and interleukin- 6 production. The release of stem cell factor by $L 929$ increased 48 hours after the treatment with SNP at $5 \mu \mathrm{g} / \mathrm{mL}$. Histologic examination showed that the inflammatory responses caused by SNA and SNP at $1 \mu \mathrm{g} / \mathrm{mL}$ were similar to the control in all experimental periods. Conclusions: It was concluded that SNA and SNP were not cytotoxic at $25 \mu \mathrm{g} / \mathrm{mL}$ or lower concentrations. However, for safe clinical use, further studies establishing others points of its toxicologic profile are recommended. (J Endod 2016;42:953-960)

\section{Key Words}

Biocompatibility, endodontic materials, inflammation, silver nanoparticles, toxicity

$\mathrm{N}$ anotechnology has emerged as a new science that involves the manipulation and creation of materials engineered at nanoscale (1). The application of this new technology has been widely spread among different areas of life including textiles, biosensors, opacifiers, bioelectronics, water filtration systems, and in the biomedical field, especially for therapeutic purposes in prostheses, catheters, and drug delivery (2). Currently, nanomaterials have been classified according to the number of external dimensions, using 1, 2, or 3 with less than $100 \mathrm{~nm}$ in nanoplates, nanofibers, or nanoparticles, respectively $(1,3)$. The small size of nanomaterials frequently results in unique physical and chemical characteristics different from the original bulk substance (4). When materials reach nanosize, they exhibit a higher surface area to volume ratio, which makes them potentially more reactive (5).

Among all the nanomaterials, clusters of silver atoms, which are defined as silver nanoparticles, are by far the ones with the highest degree of commercialization (6). Since their introduction in the 1990s as a colloidal form in ointments to prevent microbial colonization on burns, the use of silver nanoparticles has been increasing exponentially; they are currently being applied in contraceptive devices, surgical instruments, bandages, and bone prostheses $(2,7)$. In endodontic fields, silver nanoparticles have been used to inhibit microbial development and prevent infections; as a disinfectant in root canal treatments to eliminate bacteria, bacterial products, and debris from the root canal system; and also mixed with mineral trioxide aggregate (8-11). This rapid spread of silver nanoparticle use in endodontic materials was mainly because of its proven antimicrobial activity against nearly 650 different disease-causing microorganisms, including multidrugresistant strains $(4,11)$. Another reason that has encouraged the use of silver nanoparticles for therapeutic and clinical purposes was information showing that silver, in the form of nanoparticles, would be less toxic to cells and tissues (12).

It has been stated that the same properties that make silver nanoparticles interesting in various applications may have adverse effects on human health because several materials that are considered biochemically inert and biocompatible in bulk form can become toxic to different cell types in nanoscale (13). Apart from particle size, the potential cytotoxicity of silver nanoparticles has been shown to be dependent on other factors, such as shape, surface properties, or even partially

From the Departments of *Pediatric Dentistry and Public Health Dental, ${ }^{\dagger}$ Pathology and Clinical Propedeutics, ${ }^{\S}$ Basic Sciences, "Endodontics, and "Dental Materials and Prosthodontics, Araçatuba Dental School, Universidade Estadual Paulista, Araçatuba, São Paulo, Brazil; and ${ }^{\ddagger}$ Interdisciplinary Laboratory of Electrochemistry and Ceramics-Department of Chemistry, Federal University of São Carlos, São Carlos, São Paulo, Brazil.

Address requests for reprints to Dr Aline Satie Takamiya, Department of Pediatric Dentistry and Public Health Dental, Araçatuba Dental School, São Paulo State University-UNESP, José Bonifácio, 1193, Araçatuba, SP, 16015-050, Brazil. E-mail address: alinetakamiya@gmail.com $0099-2399 / \$$ - see front matter

Copyright (C) 2016 American Association of Endodontists. http://dx.doi.org/10.1016/j.joen.2016.03.014 
the presence of stabilizing agents (14). Among the stabilizing agents used in the chemical reaction method to synthesize silver nanoparticles, ammonia $\left(\mathrm{NH}_{3}\right)$ and polyvinylpyrrolidone (PVP) are some of the most frequently used to control particle growth and prevent aggregation (15). However, their profiles of toxicity have not been clearly investigated. In several studies concerning silver nanoparticle toxicity, some proposed mechanisms of action of silver nanoparticles can be found. These mechanisms are mainly attributed to the dissolution or release of silver ion from silver nanoparticles, disruption of cell membrane integrity, penetration of silver nanoparticles into the cell inducing oxidative stress, reactive oxygen species generation, interaction with protein and/or enzymes inhibiting essential cell activities, or DNA damage and apoptotic cell death (14).

Despite the efforts of several investigators and a great amount of research regarding silver nanoparticle toxicity, the exact mechanism of action of these particles and their possible risks to human health or environmental impact on several levels, such as molecular, cellular, or systemic responses in eukaryotes, have not yet been completely understood (16). Thus, considering this current panel of nanotoxicology and the possibility of incorporation of silver nanoparticles in endodontic clinics, the intention of the present study was to determine the effect of silver nanoparticles synthesized with 2 different stabilizing agents, $\mathrm{NH}_{3}$ and PVP, on a mouse fibroblast cell line (L929) by evaluating the cytotoxicity, interleukin (IL)- $1 \beta$, IL-6, and stem cell factor (SCF) production. Furthermore, we aimed to analyze the reaction of subcutaneous connective tissue of Wistar rats to these silver nanoparticles.

\section{Materials and Methods Synthesis and Characterization of Colloidal Silver Nanoparticles}

Colloidal silver nanoparticles with an average size of $5 \mathrm{~nm}$, stabilized with $\mathrm{NH}_{3}$ (Merck KGaA, Darmstadt, Germany) and PVP (Sigma-Aldrich, St Louis, MO), were prepared by the chemical reaction method based on the use of the reducing agent sodium citrate $\left(\mathrm{Na}_{3} \mathrm{C}_{6} \mathrm{H}_{5} \mathrm{O}_{7}\right)$ to reduce $\mathrm{Ag}^{+}$from silver nitrate $\left(\mathrm{AgNO}_{3}\right)$ (Merck KGaA) (15). Briefly, $7.5 \mathrm{~mL}$ of a solution of $\mathrm{Na}_{3} \mathrm{C}_{6} \mathrm{H}_{5} \mathrm{O}_{7}$ at $0.3 \mathrm{~mol} / \mathrm{L}$ was added in a trineck flask containing $150 \mathrm{~mL}$ of an aqueous solution of $\mathrm{AgNO}_{3}$ at $5.0 \times$ $10^{-3} \mathrm{~mol} / \mathrm{L}$. The solution was kept under agitation at a temperature of $90^{\circ} \mathrm{C}$ for $\sim 6$ minutes until the solution turned amber yellow, indicating the qualitative formation of silver nanoparticles. Then, $7.5 \mathrm{~mL}$ $\mathrm{NH}_{3}$ solution at $1.4 \mathrm{~mol} / \mathrm{L}$ was added to the yellow solution to stabilize the silver nanoparticles. This new colloidal solution was heated and stirred for 2 more minutes and then cooled at room temperature. In another flask, $1 \mathrm{~mL}$ of a PVP solution at $102 \mathrm{~g} / \mathrm{L}$ was added to the yellow solution after lowering the temperature. Ultraviolet/visible absorption spectroscopy (Spectrophotometer Shimadzu MultSpec-1501; Shimadzu Corporation, Tokyo, Japan) confirmed colloidal silver nanoparticle formation, and transmission electron microscopy (Electron Microscope FEG-VP Supra 35; Carl Zeiss, Jena, Germany) was used to characterize the synthesized silver nanoparticles.

\section{Cell Gulture}

Mouse fibroblast cell line (passage 3) L929 was cultured in Dulbecco modified Eagle medium (DMEM) supplemented with $10 \%$ fetal bovine serum, streptomycin $(50 \mathrm{~g} / \mathrm{mL})$, and $1 \%$ antibiotic/antimycotic cocktail (ie, $300 \mathrm{U} / \mathrm{mL}$ penicillin, $300 \mu \mathrm{g} / \mathrm{mL}$ streptomycin, $5 \mu \mathrm{g} / \mathrm{mL}$ amphotericin $\mathrm{B}$, and L-glutamine $0.3 \mathrm{~g} / \mathrm{L}$ ). All of them were purchased from GIBCO BRL (Gaithersburg, MD). Cells were maintained under standard cell culture conditions at $37^{\circ} \mathrm{C}$ in a humidified atmosphere of $95 \%$ air and $5 \% \mathrm{CO}_{2}$.

\section{In Vitro Gytotoxicity Protocol}

Cytotoxicity assessment was performed using 3-(4,5dimethylthiazol-2-yl)-2,5-diphenyltetrazolium bromide (MTT) assay; briefly, fibroblasts from cell line L929 were seeded into 24-well plates ( $10^{5}$ cells $/ \mathrm{mL}$ of medium per well). Afterward, the cells were incubated at $37^{\circ} \mathrm{C}$ in a humidified air atmosphere of $5 \% \mathrm{CO}_{2}$ for 24 hours. The exposure of the cells to silver nanoparticles was initiated at $\sim 100 \%$ of cell confluence, and the assay was done in DMEM. Colloidal silver nanoparticles, stabilized with $\mathrm{NH}_{3}$ (SNA) or PVP (SNP), were added to fibroblast culture with doses ranging from 0.1 to $100 \mu \mathrm{g} / \mathrm{mL}$. Tween 20 (Sigma-Aldrich, St Louis, MO) and culture medium were used as controls. The exposure of cell cultures to both SNA and SNP was stopped after 6, 24, and 48 hours. Viable cells were stained with formazan dye (3- [4,5dimethylthiazol-2-yl]-2,5-diphenyltetrazolium bromide [MTT']) (SigmaAldrich). Previously, MTT was dissolved in phosphate buffered saline at $5 \mathrm{mg} / \mathrm{mL}$ and, after the times of cell exposure to silver nanoparticles, stock MTT solution $(200 \mu \mathrm{L})$ was added directly to the cell culture in 24-well plates and incubated at $37^{\circ} \mathrm{C}$ for 4 hours. The MTT solution was then discarded, and $200 \mu \mathrm{L}$ isopropyl alcohol was added to each well of the 24-well plates and mixed for 30 minutes to dissolve the dark blue crystals. The blue solution was then transferred to a 96-well plate only to measure the optical density (OD) with a microplate reader (Spectra Max 190; Molecular Devices, Sunnyvale, CA) at 570-nm wavelength. All laboratory assays were performed in triplicate. The relative cell viability (\%) related to control (cell culture medium devoid of silver nanoparticles) was calculated by OD test/OD control $\times 100$, where OD test is the optical density of the test samples and OD control is the optical density of the control samples. Data were analyzed statistically by analysis of variance (ANOVA) followed by the Bonferroni correction. $P<.05$ was considered statistically significant.

\section{Determination of IL-6, IL-1 $\beta$, and SHF by Enzyme-linked Immunosorbent Assay}

The production of IL-6, IL-1 $\beta$, and SCF from cell line L929 was analyzed in the cell-free supernatants of cell culture exposed to SNA and SNP at 1.0 and $5.0 \mu \mathrm{g} / \mathrm{mL}$ after 6, 24, and 48 hours using the enzyme-linked immunosorbent assay (ELISA). Culture medium was used as the control. Antibodies and standards were purchased from PEPROTECH (Peprotech, Rocky Hill, NJ). Previously, fibroblasts from cell line L929 were seeded into 24 -well plates at $10^{5}$ cells $/ \mathrm{mL}$ of medium per well. After that, the cells were incubated at $37^{\circ} \mathrm{C}$ in a humidified air atmosphere of $5 \% \mathrm{CO}_{2}$ for 24 hours until $\sim 100 \%$ of cell confluence. The exposure of cells to silver nanoparticles was achieved in DMEM, and the laboratory assays were performed in triplicate. Cytokines were quantified according to the manufacturer's ELISA protocol. Data were analyzed statistically by ANOVA followed by the Bonferroni correction. Statistically significant differences were considered if $P$ was $<.05$.

\section{Histologic Study}

Animals. Sixteen 4- to 6-month-old male Wistar Albino rats weighing between 250 and $280 \mathrm{~g}$ were used. The animals were housed in temperature-controlled rooms and received water and food ad libitum. Their care was according to the Ethics Committee on Animal Use, Universidade Estadual Paulista, which approved the project before the experiments (protocol number FOA-0050-2010).

Polyethylene Tubes. Forty-eight polyethylene tubes (Abbott Lab of Brazil, Sao Paulo, Sao Paulo, Brazil) with a 1.0-mm internal diameter, 1.6-mm external diameter, and 10.0-mm length were used. A fibrin sponge (Technew; Rio de Janeiro, Rio de Janeiro, Brazil) was introduced into the tubes and then embedded with $100 \mu \mathrm{L}$ SNA or SNP at $1.0 \mu \mathrm{g} / \mathrm{mL}$. In the control group, the tubes received only a fibrin sponge. 
Protocol in Histologic Study. The backs of the animals were shaved under anesthesia with xylazine $(10 \mathrm{mg} / \mathrm{kg})$ and ketamine $(25 \mathrm{mg} / \mathrm{kg})$ and disinfected with $5 \%$ iodine solution. The shaved area received one 2-cm-wide incision in a head-to-tail orientation with a 15 blade (Bard-Parker, Franklin Lakes, NJ). The skin was reflected, creating 2 pockets on each side of the incision ( 1 in the caudal portion and the other in the cranial portion). The tubes were implanted into the spaces created, and the skin was closed with a 4.0 silk suture. Each animal received 3 polyethylene tubes, and 4 animals were used for each period analyzed.

After 7, 15, 30, and 90 days from the implantation time, the animals were killed by an overdose of anesthetic solution, and the tubes with surrounding tissues were removed and fixed in 10\% buffered formalin at a pH of 7.0 (International Organization for Standardization. 10993-6:2007). The tubes were then bisected transversely, and both halves were cut again longitudinally with the use of a sharp blade. This was done to allow the surfaces to be readily kept in contact with the processing solutions. The specimens were processed for glycol methacrylate (Leica Mikrosysteme Vertrieb GMBH DSA, Wetzlar, Germany) embedding, serially sectioned into $3-\mu \mathrm{m}$ cuts, and stained with hematoxylin-eosin.

Reactions in the tissue in contact with the material upon the opening of the tube were analyzed for neutrophil accumulation in 10 highpower fields $(\times 1000)$. Data were then analyzed statistically by ANOVA with the Bonferroni correction. Statistically significant differences were considered if $P$ was $<.05$.

\section{Results \\ Synthesis and Characterization of Colloidal Silver Nanoparticles}

Silver nanoparticles at $540 \mu \mathrm{g} / \mathrm{mL}$ with an average diameter of $5 \mathrm{~nm}$ were obtained through the reduction of $\mathrm{AgNO}_{3}$ with $\mathrm{Na}_{3} \mathrm{C}_{6} \mathrm{H}_{5} \mathrm{O}_{7}$ followed by stabilization with $\mathrm{NH}_{3}$ or PVP. These procedures resulted in 2 different colloidal suspensions of silver nanoparticles. In the ultraviolet/visible analysis, the absorption peak of SNP ranged from 430 to $460 \mathrm{~nm}$, characterizing silver particles in nanosize. Well-defined plasmon bands centered at $430 \mathrm{~nm}$ were revealed by the absorption spectra of the SNA and SNP colloidal suspensions (Fig. 1A). The symmetric shapes of all plasmon bands in Figure $1 A$ confirmed the colloidal stability and the particle size distribution. These bands have been commonly assigned to nanoparticles having a spherical shape.

Transmission electron microscopic observations indicated that SNA (Fig. $1 C$ ) and SNP (Fig. $1 B$ ) were well formed, spherical, and dispersed, with a mean diameter of $5 \mathrm{~nm}$. Furthermore, it was possible to note a few agglomerates of particles, mainly when stabilized by PVP (Fig. 1B).

\section{In Vitro Gytotoxicity}

The MTT assay was used to measure the cytotoxicity of both SNA and SNP to cell line L929 after exposure for 6, 24, and 48 hours. As observed in Figure $2 A$, the cytotoxicity of SNA and SNP to L929 occurred in a dose-dependent manner for all periods analyzed. MTT conversion by cells significantly decreased after SNA treatment from $15 \mu \mathrm{g} / \mathrm{mL}$ or higher doses $(P<.001)$ and after SNP treatment from 25 to $100 \mu \mathrm{g} /$ $\mathrm{mL}(P<.001)$ compared with the control at 6,24 , and 48 hours. Additionally, between the 2 types of silver nanoparticles tested at concentrations from 2.5 to $100 \mu \mathrm{g} / \mathrm{mL}$, SNA was significantly more cytotoxic at the 3 different times evaluated $(P<.001)$.

Interestingly, it was observed that cell exposure to SNA (0.1$5.0 \mu \mathrm{g} / \mathrm{mL})$ and SNP $(0.1-15.0 \mu \mathrm{g} / \mathrm{mL})$ for 6 hours significantly increased the cell proliferation compared with the control $(P<.001)($ Fig. $2 A)$.

\section{Determination of IL-6, IL-1 $\beta$, and SCF by ELISA}

Cell line L929 was exposed to 1 and $5 \mu \mathrm{g} / \mathrm{mL}$ colloidal silver nanoparticles stabilized with $\mathrm{NH}_{3}$ or PVP for 6, 24, and 48 hours. IL-6, IL-1 $\beta$, and SCF production was constitutively detected in the cell supernatants
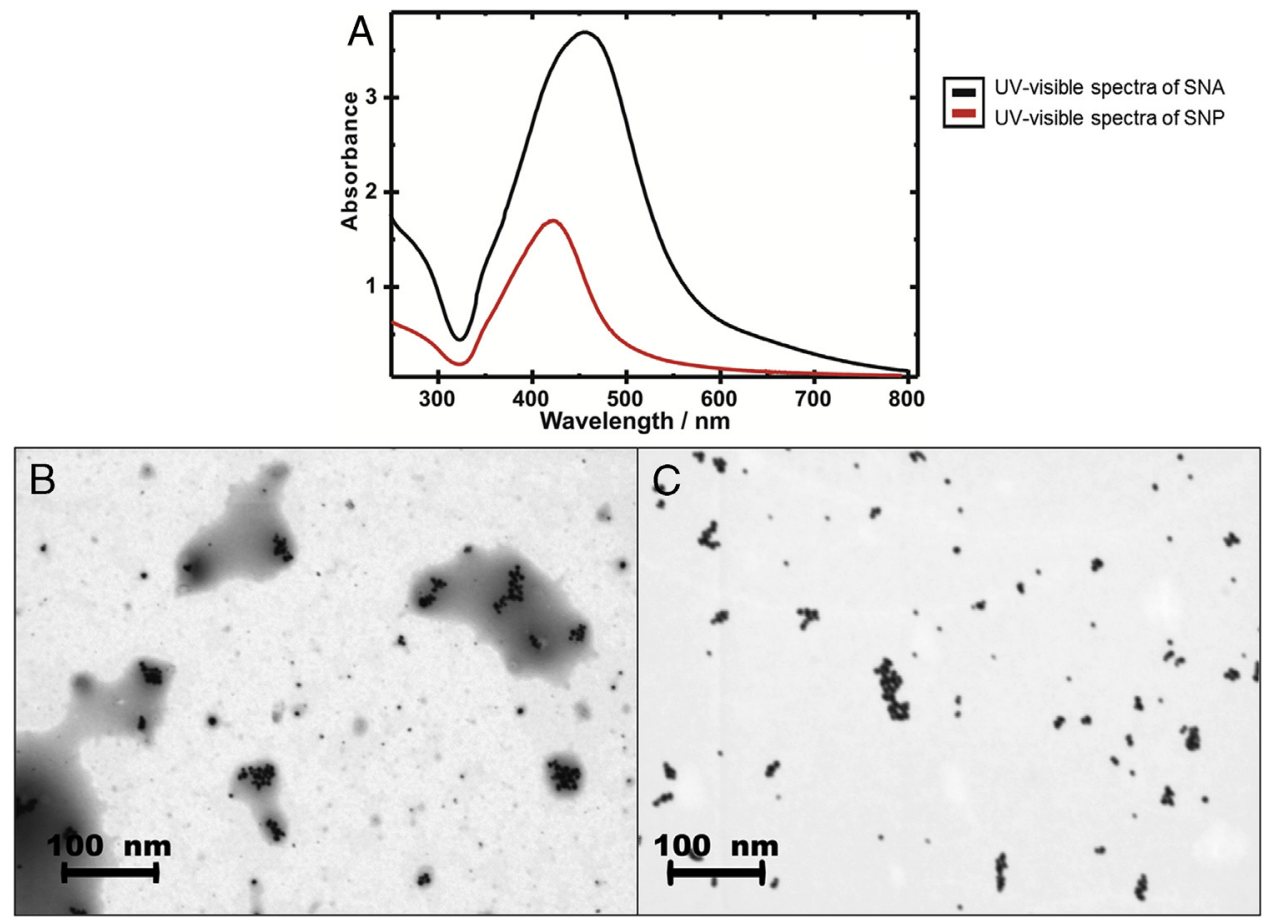

Figure 1. (A) Ultraviolet-visible spectra of colloidal silver nanoparticles $(5 \mathrm{~nm})$ stabilized with ammonia and polyvinylpyrrolidone; transmission electron microscopic images of colloidal silver nanoparticles with $5 \mathrm{~nm}$ stabilized with $(B)$ PVP and $(C)$ ammonia. 

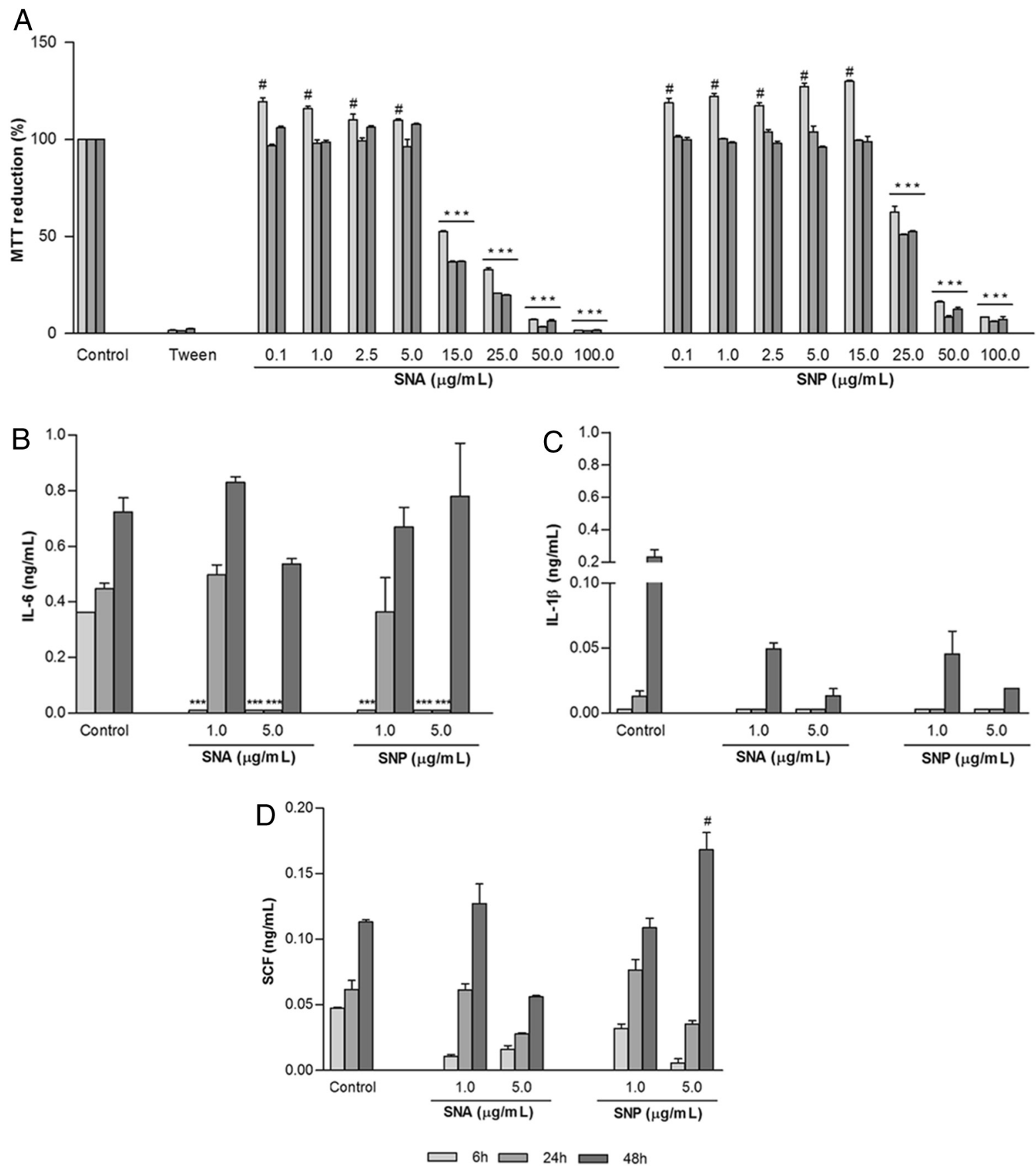

Figure 2. (A) Cytotoxicity of SNA $5 \mathrm{~nm}$ and SNP $5 \mathrm{~nm}$ to fibroblasts (L929) after 6, 24, and 48 hours of treatment expressed as a percentage. The mean levels of proinflammatory cytokine $(B)$ IL-6, $(C)$ IL-1 $\beta$, and $(D)$ SCF produced by fibroblasts (L929) in the presence of different concentrations of silver nanoparticles stabilized by ammonia (SNA) $5 \mathrm{~nm}$ or polyvinylpyrrolidone (SNP) $5 \mathrm{~nm}$ after 6,24, and 48 hours expressed as pg/mL. Error bars indicate the standard deviations of the means. ***:Significant decrease $(P<.001)$ and \#significant increase $(P<.001)$ compared with the control group using ANOVA with the Bonferroni correction.

as shown in Figure 2. ELISA analysis of cell-free supernatants exposed to both concentrations of silver nanoparticles did not show significant increases in levels of IL- 6 and IL- $1 \beta$ for the 3 different periods analyzed when compared with the control samples (Fig. $2 B$ and $C$ ). However, it was observed that SNA and SNP reduced IL- 6 production at $1 \mu \mathrm{g} / \mathrm{mL}$ at 6 hours and at $5 \mu \mathrm{g} / \mathrm{mL}$ at 6 and 24 hours compared with the control $(P<.001)$ (Fig. $2 B)$.

The SCF level was significantly increased only in the concentration of SNP at $5 \mu \mathrm{g} / \mathrm{mL}$ after 48 hours compared with the control group $(P<.001)$ (Fig. 2D).

\section{Histologic Study}

Histologic analysis was performed after 7, 15, 30, and 90 days according to ISO 10993-6, which specifies test methods for the assessment of local effects after implantation of biomaterials intended for use in medical devices or to be applied topically in clinical indications (International Organization for Standardization, 2007).

In the control group (fibrin), it was possible to observe a moderate inflammatory response in the tissue around the implanted tubes on the 7 th and 15 th days, with granulation tissue containing mainly neutrophils. There were young fibroblasts over this area in a disorganized 
distribution (Fig. $3 A-D$ ). From 30 up to 90 days after implantation, there was a mild inflammatory infiltrate with reduction in the number of inflammatory cells in a thin fibrous capsule with well-organized collagen fibers (Fig. $3 \boldsymbol{E}-\boldsymbol{H}$ ).

In sections obtained on days 7 and 15 after the implantation of tubes containing fibrin embedded with SNA or SNP at a concentration of $1 \mu \mathrm{g} / \mathrm{mL}$, it was possible to observe the presence of a granulation tissue containing neutrophils in a moderate inflammatory reaction (Fig. 3I-L and $Q-T$ ). Mild inflammatory cell infiltration and a reduction in the thickness of the fibrous capsule were evident from day 30 onward, similar to the control group (Fig. $3 M-P$ and $U-Y$ ). There were no statistically significant differences among the number of neutrophils for the different types of silver nanoparticles at $1 \mu \mathrm{g} / \mathrm{mL}$ in all periods analyzed compared with the control $(P>.05)$ (Fig. 3Z). The numbers of lymphocytes, macrophages, and eosinophils in the sites of inflammation were nonsignificant (data not shown).

\section{Discussion}

The purpose of the present study was to evaluate the potential of toxicity and the effect of SNA and SNP in an in vitro mouse fibroblast cell line (L929) and in subcutaneous connective tissue of Wistar rats, analyzing the inflammatory response after the implantation of the particles in the subcutaneous tissue. The research hypotheses that SNA and SNP do not cause toxic effects on fibroblast cells and tissue inflammatory reactions independent of the concentration, time of exposure, and type of stabilizing agent was rejected because silver nanoparticles showed decreased mitochondrial function in fibroblasts, and this effect was dependent on the concentration of the particles and the stabilizer agent.

The results evaluating the cytotoxicity of both SNA and SNP were dose dependent to L929. These data are in agreement with another previous study that, although having used different experimental conditions, reported that silver nanoparticles caused dose-dependent toxicologic responses, inducing severe morphologic abnormalities, disruption of the mitochondrial respiratory chain, DNA damage, and apoptosis (13). Zanette et al (17) also found concentrationdependent cytotoxicity after treating epithelial cells (HaCaT) with 10$\mathrm{nm}$ silver nanoparticles at concentrations that ranged from 0.006 to $333 \mu \mathrm{mol} / \mathrm{L}$.

In Figure $2 A$, it is possible to observe that SNP caused a cytotoxic effect with a significant reduction in the number of viable cells at silver concentrations greater or equal to $25 \mu \mathrm{g} / \mathrm{mL}$ for all experimental periods. On the other hand, SNA induced significant cytotoxicity from lower concentrations $(15 \mu \mathrm{g} / \mathrm{mL}$ or higher). Several previous studies investigating the effect of silver nanoparticles on different cell lines also reported toxic responses with similar concentrations used in this study, such as in mouse fibroblast cells (50 and $100 \mu \mathrm{g} / \mathrm{mL}$ ), alveolar macrophages (10-75 $\mu \mathrm{g} / \mathrm{mL})$, human dermal fibroblasts (10-200 $\mu \mathrm{g}$ / $\mathrm{mL})$, and human intestinal cells $(5-100 \mu \mathrm{g} / \mathrm{mL})(2,18-20)$. As observed, SNA was significantly more cytotoxic to L929 than SNP in almost all concentrations analyzed. Herein, silver colloidal suspensions were prepared with $\mathrm{NH}_{3}$ or PVP as stabilizers. $\mathrm{NH}_{3}$ stabilizes metallic silver nanoparticles inducing soluble diamine silver complexes, which trap free silver ions responsible for the increase of particle size (15). The PVP polymer bonds to silver nanoparticle surfaces through the nitrogen atom in their molecule, resulting in a flocculation process (21). Despite the flocculation, the chain of the polymer molecule keeps the silver nanoparticles separated from each other, and the particles are able to interact with the cells because of their high surface energy and mobility (21).

Soluble diamine silver complex present in the colloidal SNA might have potentiated its cytotoxic effect on L929. According to El Badawy et al (14), silver nanoparticle toxicity may be partially attributed to the pres- ence of impurities such as silver ion and residual reducing and stabilizing agents from silver nanoparticle synthesis because the removal of the residual impurities showed a strong impact on reducing the toxicity of silver nanoparticles. On the other hand, the presence of polymer PVP, which forms a core-shell structure with silver nanoparticles, may have interfered in the process of interaction of the SNP with the cells, thus producing the lower cytotoxic effect observed in the present study $(22,23)$. Tan et al (23), in agreement with our results, have also found that PVPcoated nanosilver aggregates were efficiently internalized by the cells through the endocytosis process and showed improved biocompatibility to HeLa cells compared with uncoated nanosilver. The results observed by Mei et al (22) also corroborate with our findings because silver nanoparticles synthesized in the presence of a polymer promoted a good cytocompatibility to NIH3T3 cells and allowed dermal healing in diabetic rats with damaged immune systems.

In the present study, increased cell proliferation was observed after treatment with SNA and SNP in lower concentrations at 6 hours. These data are in agreement with a previous study that, although having used higher concentrations (50 and $100 \mu \mathrm{g} / \mathrm{mL}$ ) of silver nanoparticles, also described increased cell proliferation (24). Sur et al (25) observed that silver nanoparticles modified with glucose and lactose induced increased cell proliferation in the initial periods of treatment, decreasing with increased incubation time. According to Rosas-Hernández et al (24), the proliferative effect caused by silver nanoparticles in the initial period of treatment is dependent on nitric oxide synthesis by the cell. Furthermore, the increased proliferation caused by silver nanoparticles at 6 hours may be attributed to reduced uptake of particles in this period (25).

The release of proinflammatory cytokines, such as IL- $1 \beta$ and IL- 6 , by fibroblasts mediating inflammatory and immunologic responses after exposure to irritants has been reported $(19,26)$. In light of this, we have analyzed the release of these cytokines by L929 after exposure to both SNA and SNP. The results showed that cell exposure to these 2 types of silver nanoparticles did not cause a significant release of IL-6 and IL$1 \beta$ for all periods analyzed. Contrarily, Samberg et al (27) reported that human epidermal keratinocytes challenged by silver nanoparticles released significant amounts of IL- $1 \beta$ after 24 hours of treatment. There are some possible reasons that may explain this difference. First, the study by Samberg et al used carbon-coated silver nanoparticles, whereas the current study tested silver nanoparticles stabilized with $\mathrm{NH}_{3}$ and PVP. Second, the current study used particles with an average diameter of $5 \mathrm{~nm}$, whereas the Samberg study used larger silver nanoparticles with 20, 50, and $80 \mathrm{~nm}$. Finally, the Samberg study evaluated the human epidermal keratinocyte responses, whereas the current study assessed the capacities of silver nanoparticles to activate mouse fibroblast (L929) responses.

Regarding IL-6, a cytokine that can play a proinflammatory role in the presence of irritants, it was observed that SNA and SNP treatment was able to reduce IL- 6 production at 6 and 24 hours. Greulich et al (28) have reported that silver nanoparticles $(100 \mathrm{~nm})$ at a concentration of $2.5 \mu \mathrm{g} / \mathrm{mL}$ significantly decreased IL-6 production by human mesenchymal stem cells after 7 days of treatment. This reduction in IL-6 production observed in the present study might be suitable for endodontic treatment materials because IL-6 generation induces neutrophil chemotaxis and increases the pulp vascular permeability contributing to pulp inflammation $(26,29)$. On the other hand, the results observed in the present report were different from the findings from another study wherein IL-6 release by human fibroblasts (IMR-90) that were exposed to silver nanoparticles of 6-20 nm was significant after 48 hours (30). These dual effects observed in the literature in relation to IL- 6 production compared with our study may be caused by the difference in the cell line and the size and type of the silver nanoparticles. 


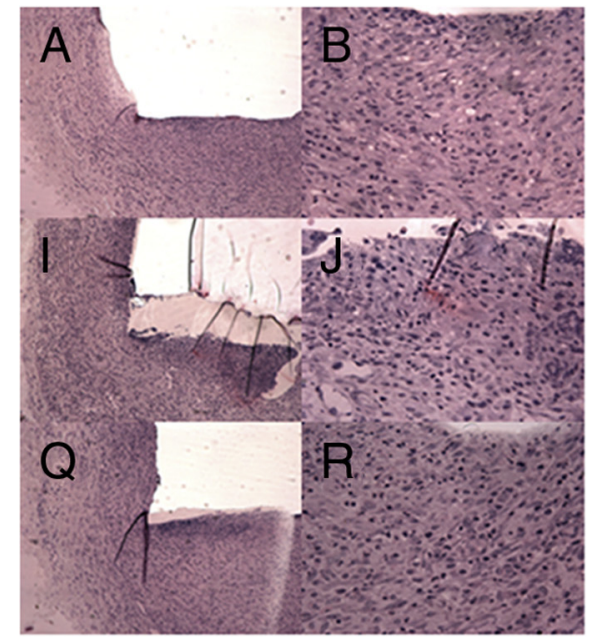

7 days

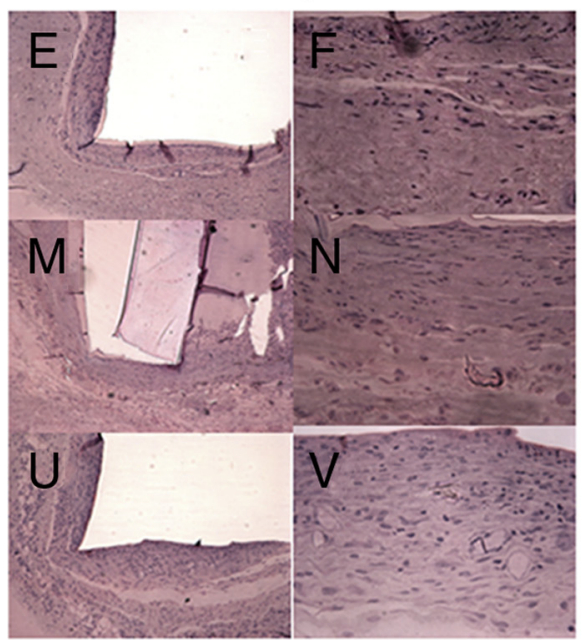

30 days

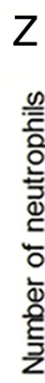

Z

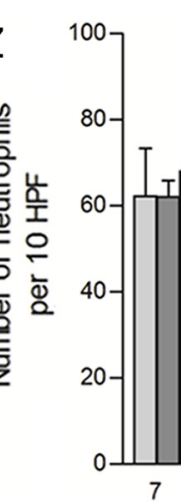

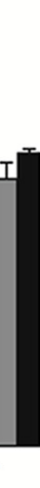

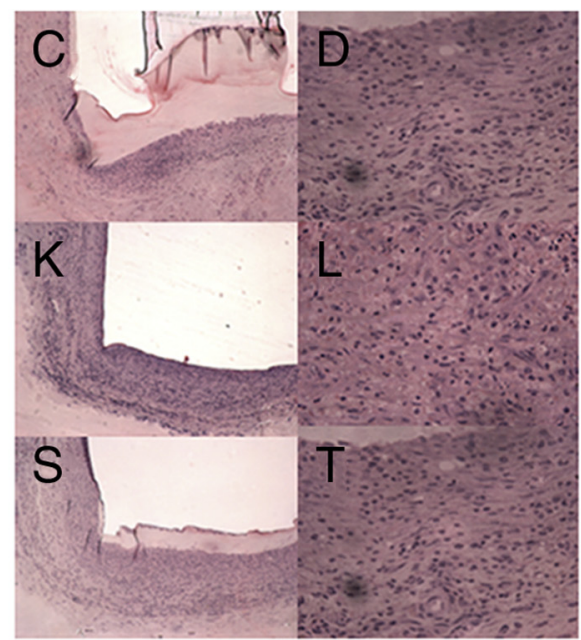

15 days

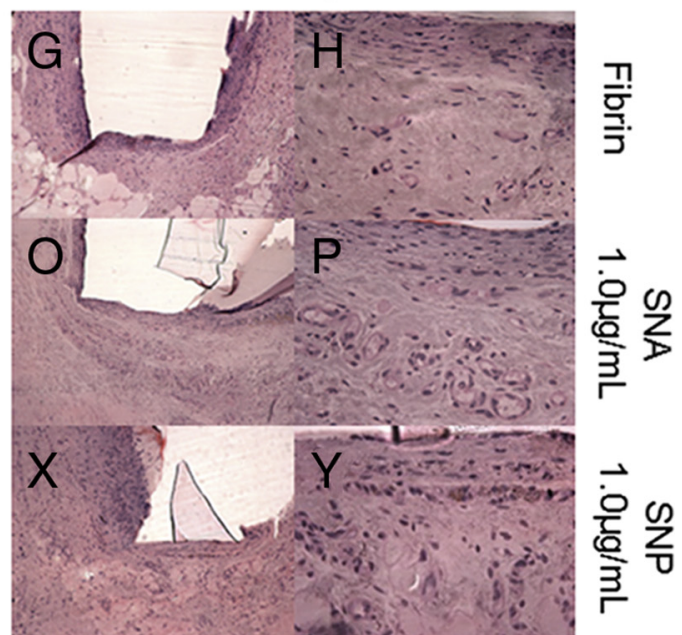

90 days

\section{Fibrin (Control) \\ $\mathrm{SNA} 1.0 \mathrm{mg} / \mathrm{mL}$ \\ SNP $1.0 \mathrm{mg} / \mathrm{mL}$}

90

\section{Days after implantation}

Figure 3. Tissue reaction in contact with the material on the tube openings after 7, 15,30, and 90 days of implantation (hematoxylin-eosin staining, $\times 10$ and $\times 40$ ). $(A)$ Control (fibrin) 7 days, moderate cell inflammatory infiltration consisting mainly of neutrophils, $\times 10$; $(B)$ control (fibrin) 7 days $\times 40$; $(C)$ control (fibrin) 15 days, moderate cell inflammatory infiltration consisting mainly of neutrophils, $\times 10 ;(D)$ control (fibrin) 15 days $\times 40 ;(E)$ control (fibrin) 30 days, mild cell inflammatory infiltration consisting mainly of neutrophils, $\times 10 ;(F)$ control (fibrin) 30 days $\times 40 ;(G)$ control (fibrin) 90 days, mild cell inflammatory infiltration consisting mainly of neutrophils, $\times 10 ;(H)$ control (fibrin) 90 days, $\times 40$; (I) SNA $1 \mu \mathrm{g} / \mathrm{mL} 7$ days, moderate cell inflammatory infiltration consisting mainly of neutrophils, $\times 10 ;(J) \mathrm{SNA} 1 \mu \mathrm{g} / \mathrm{mL} 7 \mathrm{days}, \times 40 ;(K) \mathrm{SNA} 1 \mu \mathrm{g} / \mathrm{mL}$ 15 days, moderate cell inflammatory infiltration consisting mainly of neutrophils, $\times 10 ;(L)$ SNA $1 \mu \mathrm{g} / \mathrm{mL} 15$ days, $\times 40 ;(M)$ SNA $1 \mu \mathrm{g} / \mathrm{mL} 30$ days, mild cell inflammatory infiltration consisting mainly of neutrophils, $\times 10$; (N) SNA $1 \mu \mathrm{g} / \mathrm{mL} 30$ days, $\times 40 ;(O) \mathrm{SNA} 1 \mu \mathrm{g} / \mathrm{mL} 90$ days, mild cell inflammatory infiltration consisting mainly of neutrophils, $\times 10$; (P) SNA $1 \mu \mathrm{g} / \mathrm{mL} 90$ days, $\times 40 ;(Q)$ SNP $1 \mu \mathrm{g} / \mathrm{mL} 7$ days, moderate cell inflammatory infiltration consisting mainly of neutrophils, $\times 10 ;(R)$ SNP $1 \mu \mathrm{g} / \mathrm{mL} 7 \mathrm{days}, \times 40 ;(S)$ SNP $1 \mu \mathrm{g} / \mathrm{mL} 15$ days, moderate cell inflammatory infiltration consisting mainly of neutrophils, $\times 10 ;(T) \mathrm{SNP} 1 \mu \mathrm{g} / \mathrm{mL} 15$ days, $\times 40 ;(U) \mathrm{SNP} 1 \mu \mathrm{g} / \mathrm{mL} 30$ days, mild cell inflammatory infiltration consisting mainly of neutrophils, $\times 10 ;(V)$ SNP $1 \mu \mathrm{g} / \mathrm{mL} 30$ days, $\times 40 ;(X)$ SNP $1 \mu \mathrm{g} / \mathrm{mL} 90$ days, mild cell inflammatory infiltration consisting mainly of neutrophils, $\times 10$; and $(Y)$ SNP $1 \mu \mathrm{g} / \mathrm{mL} 90$ days, $\times 40$. Neutrophil recruitment in the tissue around the implanted tubes was counted in 10 high-power fields $(\times 1000$ magnification). $(Z)$ Mean values of the cells after 7, 15, 30, and 90 days of implantation of tubes containing SNA $5 \mathrm{~nm}$ or SNP $5 \mathrm{~nm}$. Error bars indicate the standard deviations of the means. 
Concerning the SCF, it was observed that only SNP at $5 \mu \mathrm{g} / \mathrm{mL}$ after 48 hours of treatment was able to induce significant SCF release. SCF has been reported to contribute to the inflammatory response by inducing dental pulp and gingival fibroblast proliferation (31). Reber et al (32) reported that the levels of SCF can increase in the early stages of tissue regeneration from 24 until 72 hours, when mast cell activation seems to be necessary, decreasing subsequently on day 14 to the baseline level. In this way, it is possible that the increase of SCF production observed in our study at 48 hours assists in the attenuation of the initial inflammatory response, contributing to tissue repair.

To further clarify the biocompatibility of silver nanoparticles, a model of implantation in the subcutaneous tissue of rats was also used, which is 1 of the most appropriate tests to determine the local effects of compounds $(8,33)$. In the present study, we have analyzed the tissue reaction to SNA and SNP at $1.0 \mu \mathrm{g} / \mathrm{mL}$. This concentration was taken into account because of previous results obtained from in vitro analysis with the cytotoxicity assays. This concentration corresponded to a nontoxic concentration of SNA and SNP to L929.

Initially, after 7 days, a moderate inflammatory response consisting primarily of neutrophils was observed, which was reduced with time. Similar results with a mild tissue reaction were obtained with silver nanoparticles at $23 \mathrm{ppm}(23 \mu \mathrm{g} / \mathrm{mL})$ that were also implanted in subcutaneous tissue of rats by Gomes-Filho et al (8). In our results, the tissue reaction induced by implantation of the 2 types of silver nanoparticles at $1.0 \mu \mathrm{g} / \mathrm{mL}$ did not show any significant statistical difference compared with the control group in all periods analyzed. Contrarily, Xu et al (34) showed that after intravenous administration of silver nanoparticles, the area showed severe inflammatory cell infiltration on day 7 , but these changes significantly diminished on day 14 , allowing subsequent normal tissue healing. Chen et al (35) reported that after implanting silver nanoparticles into the rat's back muscle, a serious inflammatory response with granuloma formation and a large number of macrophages around the implanted particles were observed even after 90 and 180 days. It is important to emphasize that in Chen's study, silver nanoparticles smaller than $100 \mathrm{~nm}$ were obtained from Sigma-Aldrich and were implanted intramuscularly. In the Xu study, the administration was intravenous, and the particles had an average size of $15 \mathrm{~nm}$, which could in part explain the difference in the inflammatory response observed.

There is a large interval between the in vitro and in vivo study. It is import to clarify that the in vivo study analyzed the cytotoxicity at earlier times (6, 24, and 48 hours), aiming to define the initial profile of cellular response to silver nanoparticles. Afterward, with the intention of evaluating the tissue reaction to silver nanoparticles in a larger period, we used an animal model with analysis at 7, 15, 30, and 90 days. Shorter periods corresponding to those used in the in vitro study were not evaluated because before the 7 th day we have acute inflammatory response resulting from the surgical procedure, which makes it difficult to analyze the response to silver nanoparticles singly. After 7 days, the surgical trauma was healed, and the inflammatory reaction observed was to silver nanoparticles.

In summary, our results showed that SNA and SNP exposure affected the cell (L929) viability in a concentration-dependent manner. The type of stabilizing agent interfered with the SNP cytotoxicity being less toxic to L929 than SNA. However, the ability of SNA and SNP to stimulate $\mathrm{L} 929$ to produce proinflammatory cytokines was not observed. In addition, both SNA and SNP at $1 \mu \mathrm{g} / \mathrm{mL}$ did not induce significant inflammatory responses in subcutaneous tissue of the rats, suggesting that the silver nanoparticles at this concentration may be considered biocompatible.

Finally, however, despite the in vitro and in vivo data obtained in the present study showing that SNA and SNP may be considered biocom- patible at low doses, further studies concerning the toxicology of silver nanoparticles in different cell lines and in vivo studies related to the distribution and accumulation of silver nanoparticles after different types of exposition should be performed. Investigating the effects of chronic low-dose silver nanoparticle exposure for elucidating the exact manner wherein these particles interact with the organisms, establishing their toxicologic profile, and ensuring their safe application in endodontic treatments is strongly recommended.

\section{Acknowledgments}

The authors thank COMF/CEPID and INCTMNFAPESP-CNPq (grant no. 2013/07296-2) for preparing and characterizing the colloidal suspensions of SNA and SNP. Supported by São Paulo Research Foundation (FAPESP), Brazil (grant no. 2010/05788-7).

The authors deny any conflicts of interest related to this study.

\section{References}

1. Kaehler T. Nanotechnology: basic concepts and definitions. Clin Chem 1994;40: 1797-9.

2. Arora S, Jain J, Rajwade JM, et al. Interactions of silver nanoparticles with primary mouse fibroblasts and liver cells. Toxicol Appl Pharmacol 2009;236:310-8.

3. Chairuangkitti P, Lawanprasert S, Roytrakul S, et al. Silver nanoparticles induce toxicity in A549 cells via ROS-dependent and ROS-independent pathways. Toxicol In Vitro 2013;27:330-8.

4. Monteiro DR, Gorup LF, Takamiya AS, et al. The growing importance of materials that prevent microbial adhesion: antimicrobial effect of medical devices containing silver. Int J Antimicrob Agents 2009;34:103-10.

5. Beer C, Foldbjerg R, Hayashi Y, et al. Toxicity of silver nanoparticles - nanoparticle or silver ion? Toxicol Lett 2012;208:286-92.

6. Hobson DW. Commercialization of nanotechnology. Wiley Interdiscip Rev Nanomed Nanobiotechnol 2009;1:189-202.

7. Foldbjerg R, Olesen P, Hougaard M, et al. PVP-coated silver nanoparticles and silver ions induce reactive oxygen species, apoptosis and necrosis in THP-1 monocytes. Toxicol Lett 2009; 190:156-62.

8. Gomes-Filho JE, Silva FO, Watanabe S, et al. Tissue reaction to silver nanoparticles dispersion as an alternative irrigating solution. J Endod 2010;36:1698-702.

9. Bahador A, Pourakbari B, Bolhari B, et al. In vitro evaluation of the antimicrobial activity of nanosilver-mineral trioxide aggregate against frequent anaerobic oral pathogens by a membrane-enclosed immersion test. Biomed J 2015;38:77-83.

10. Wu D, Fan W, Kishen A, et al. Evaluation of the antibacterial efficacy of silver nanoparticles against Enterococcus faecalis biofilm. J Endod 2014;40:285-90.

11. Samiei M, Farjami A, Dizaj SM, et al. Nanoparticles for antimicrobial purposes in endodontics: a systematic review of in vitro studies. Mater Sci Eng C Mater Biol Appl 2016:58:1269-78.

12. Edwards-Jones $V$. The benefits of silver in hygiene, personal care and healthcare. Lett Appl Microbiol 2009;49:147-52.

13. Wei L, Tang J, Zhang Z, et al. Investigation of the cytotoxicity mechanism of silver nanoparticles in vitro. Biomed Mater 2010;5:044103.

14. El Badawy AM, Silva RG, Morris B, et al. Surface charge-dependent toxicity of silver nanoparticles. Environ Sci Technol 2011;45:283-7.

15. Gorup LF, Longo E, Leite ER, et al. Moderating effect of ammonia on particle growth and stability of quasi-monodisperse silver nanoparticles synthesized by the Turkevich method. J Colloid Interface Sci 2011:360:355-8.

16. Ahamed M, Karns M, Goodson M, et al. DNA damage response to different surface chemistry of silver nanoparticles in mammalian cells. Toxicol Appl Pharmacol 2008; 233:404-10.

17. Zanette C, Pelin M, Crosera M, et al. Silver nanoparticles exert a long-lasting antiproliferative effect on human keratinocyte HaCaT cell line. Toxicol In Vitro 2011; 25:1053-60.

18. Braydich-Stolle LK, Lucas B, Schrand A, et al. Silver nanoparticles disrupt GDNF/Fyn kinase signaling in spermatogonial stem cells. Toxicol Sci 2010;116:577-89.

19. Carlson C, Hussain SM, Schrand AM, et al. Unique cellular interaction of silver nanoparticles: size-dependent generation of reactive oxygen species. J Phys Chem B 2008;112:13608-19.

20. Hussain SM, Hess KL, Gearhart JM, et al. In vitro toxicity of nanoparticles in BRL 3A rat liver cells. Toxicol In Vitro 2005;19:975-83.

21. Kvitek L, Panacek A, Soukupova J, et al. Effect of surfactants and polymers on stability and antibacterial activity of silver nanoparticles (NPs). J Phys Chem C 2008; 112:5825-34. 
22. Mei L, Lu Z, Zhang X, et al. Polymer-Ag nanocomposites with enhanced antimicrobial activity against bacterial infection. ACS Appl Mater Interfaces 2014;6:15813-21.

23. Tan X, Wang Z, Yang J, et al. Polyvinylpyrrolidone- (PVP-) coated silver aggregates for high performance surface-enhanced Raman scattering in living cells. Nanotechnology 2009;20:445102.

24. Rosas-Hernández H, Jimenez-Badillo S, Martinez-Cuevas PP, et al. Effects of 45-nm silver nanoparticles on coronary endothelial cells and isolated rat aortic rings. Toxicol Lett 2009;191:305-13.

25. Sur I, Cam D, Kahraman M, et al. Interaction of multi-functional silver nanoparticles with living cells. Nanotechnology 2010;21:175104.

26. Azuma MM, Samuel R0, Gomes-Filho JE, et al. The role of IL-6 on apical periodontitis: a systematic review. Int Endod J 2014;47:615-21.

27. Samberg ME, Oldenburg SJ, Monteiro-Riviere NA. Evaluation of silver nanoparticle toxicity in skin in vivo and keratinocytes in vitro. Environ Health Perspect 2010; 118:407-13.

28. Greulich C, Kittler S, Epple M, et al. Studies on the biocompatibility and the interaction of silver nanoparticles with human mesenchymal stem cells (hMSCs). Langenbecks Arch Surg 2009;394:495-502.
29. Chang SW, Bae WJ, Yi JK, et al. Odontoblastic differentiation, inflammatory response, and angiogenic potential of 4 calcium silicate-based cements: Micromega MTA, ProRoot MTA, RetroMTA, and experimental calcium silicate cement. J Endod 2015;41: 1524-9.

30. Asharani P, Sethu S, Lim HK, et al. Differential regulation of intracellular factors mediating cell cycle, DNA repair and inflammation following exposure to silver nanoparticles in human cells. Genome Integr 2012;3:2.

31. Oliveira SH, Santos VA. Lipopolysaccharide-induced stem cell factor messenger RNA expression and production in odontoblast-like cells. J Endod 2012;38:623-7.

32. Reber L, Da Silva CA, Frossard N. Stem cell factor and its receptor c-Kit as targets for inflammatory diseases. Eur J Pharmacol 2006;533:327-40.

33. Gomes-Filho JE, Gomes AC, Watanabe S, et al. Evaluation of tissue reaction, cell viability and cytokine production induced by Sealapex Plus. J Appl Oral Sci 2011; 19:329-36.

34. Xu L, Li X, Takemura T, et al. Genotoxicity and molecular response of silver nanoparticle (NP)-based hydrogel. J Nanobiotechnology 2012;10:16.

35. Chen D, Xi T, Bai J. Biological effects induced by nanosilver particles: in vivo study. Biomed Mater 2007;2:S126-8. 